\section{Poster Presentations - Nursing}

\section{DO MOTHERS AND FATHER TO PRETERM EVALUATE THEIR EXPERIENCE OF STRESS AND NURSE'S SUPPORT DIFFERENTLY WHEN HOSPITALIZED IN A NICU?}

doi:10.1136/archdischild-2012-302724.1845

'BS Tandberg, ${ }^{2} \mathrm{HP}$ Sandtrø, ${ }^{3} \mathrm{M}$ Vårdal, ${ }^{2} \mathrm{~A}$ Rønnestad. ${ }^{1}$ Pediatric, Vestre Viken Hospital Trust, Drammen; 'Department of Pediatrics, Oslo University Hospital, Rikshospitalet; ${ }^{3}$ Department of Biostatistic and Epidemiology, Oslo University Hospital, Oslo, Norway

Background Studies show that mothers and fathers of a premature infant have high levels of stress. Studies also confirm the importance of nursing support to reduce stress of parents.

Aim To explore gender differences in experiencing parental stress and nursing support of mothers and fathers who become parents to premature infants and receive standard care.

Methods Mothers and fathers $(\mathrm{N}=82)$ answered two self reporting questionnaires, the Nurse Parent Support Tool (NPST) once and the Parental Stressor Scale (PSS: NICU) twice. The NPST consists of 21 items classified into four dimensions, information, appraisal, emotional support and nursing care. The PSS: NICU is designed to measure parental perception of stressors arising from the physical and psychosocial environment of the NICU.

Result At baseline both mothers and fathers experienced high stress levels in relation to the infants appearance, some to the parental role and alteration and less on the dimension of sight and sound. The fathers' experienced higher levels of stress at follow up compared to baseline for a number of variables. There were no significant differences regarding parents' experiences with support from nurses.

Conclusion Mothers' experiences of stress decrease but fathers reports increased stress at discharge to home compared to their responses at baseline. In spite of this both parents were satisfied with the support from nurses, especially in relation to the information dimension and the nursing care dimension. As a result of this study we have become aware of the importance of stress preventing initiatives towards fathers of "healthy" premature infants.

\section{ASSESSMENT OF SOUND LEVELS IN A NEONATAL INTENSIVE CARE UNIT IN ALZAHRA TEACHING HOSPITAL IN TABRIZ, IRAN}

doi:10.1136/archdischild-2012-302724.1846

'MB Hosseini, ${ }^{2}$ S Valizadeh, ${ }^{3} \mathrm{NS}$ Alavi. 'Neonatology, Pediatrics; ${ }^{2}$ School of Nursing and Midwifery; ${ }^{3}$ Nursing \& Midwifery Faculty, Tabriz University of Medical Sciences, Tabriz, Iran

Introduction The maleffects of loud noise on preterm infants have been recognized for years and the necessity of measuring the noise level and its reduction in NICU has been proven to the Neonatologists.

Aim This study aims to evaluate the noise level of NICU in Tabriz Alzahra hospital and compare it with the standard level and also to specify the noise producing sources.

Materials and Methods 24 accidental, continuous hours were selected in four working days and the Leq, L10, Lmax and Lzpeak variables were measured in six fixed spots of NICU ward using a sound level meter based on dBA.

Results The mean of noise levels gained in the form of Leq $(M=63.46$ $d B), L 10(M=65.81 d B), \operatorname{Lmax}(M=71-24 d B)$ in six different spots and hours of measurement was higher than the standard level (NICU $\mathrm{Leq}=45 \mathrm{~dB}, \mathrm{~L} 10=50 \mathrm{~dB}, \mathrm{Lmax}=65 \mathrm{~dB})$. There was no significant difference in the noise level of the six spots measured. The loudest Leq belonged to the round hours of the nurses and had a direct relationship with the number of people present in the ward. The least Leq was related to the time when the fewest number of people were present in the ward. Based on their intensity, the noise producing sources were application of metal equipments and dropping them, presence of students, nurse rounds, physicians' rounds, alarms of devices and the wheels of portable trolleys, respectively.

Conclusion Noise level in NICU ward is higher than the standard level, it is necessary to take measures for the purpose of reducing it.

\section{CLINICANS DOCUMENTATION OF OXYGENATION AND VENTILATION IN PREMATURE AND SICK NEWBORNS IN A NORWEGIAN NEONATAL INTENSIVE CARE UNIT (NICU)}

doi:10.1136/archdischild-2012-302724.1847

'MT Solberg, ${ }^{2}$ TWR Hansen, 'IT Bjørk. 'Department of Nursing Science, University of Oslo; 'Institute of Clinical Medicine, Faculty of Medicine, University of Oslo, Oslo, Norway

Background and Aims Clinical practice concerning oxygen assessment and administration varies between nurses. Ventilator management, pulse oximetry alarm settings and monitoring also varies greatly. Clinicians would benefit from analysis of what they should do to effectively improve the outcomes and avoid hyperventilation and hyperoxia in newborns. The aim of this study was to investigate how nurses documented oxygenation and ventilation in premature and sick newborns on respirator treatment.

Method This was a retrospective study (2010-2011) of the documented oxygen treatment from one NICU in Norway. Based on research literature and clinical practice, variables for oxygen treatment in preterm and sick newborns on respirator were defined. A power analysis resulted in the inclusion of 138 newborns. The diagnoses were defined in four categories classified by ICD -10 (KITHHealth Affairs); immature lungs, lung problems, circulation problems and infection. We estimated the proportion of newborns where oxygen saturation was documented outside the recommended limit of 88-93\%.

Results At this time we have the results from 110 cases, constituting documentation from 3904 hours of respirator time. We compared the oxygen saturation, $\mathrm{PaCO}_{2}$ and $\mathrm{PaO}_{2}$ values in relation to disease conditions and oxygen administration in the premature and sick newborns. We will report statistics on these variables.

Conclusions These results will be incorporated in an action research study. Clinicians in the NICU will reflect and evaluate on the results in order to develop best practice in oxygenation and ventilation.

\section{GENTLE HUMAN TOUCH AND YAKSON: THE EFFECT ON PRETERM'S BEHAVIORAL REACTIONS}

doi:10.1136/archdischild-2012-302724.1848

F Eshghi. Kerman University of Medical Sciences, Razi Faculty of Nursing and Midwifry, Kerman, Iran

Objective Touch is one of the first strong positive senses that develop in neonate. Therapeutic touch could be considered as a complementary treatment in Neonate intensive care units (NICU). Design This quasi experimental study was conducted to compare the effect of Yakson and GHT on behavioral reaction of preterm infants hospitalized in NICU in South-East of Iran.

Patients 90 preterm infants participated in this study. They randomly divided into 3 groups: 1) Yakson group, $n=30,2)$ GHT group, $\mathrm{n}=30,3$ ) control group, $\mathrm{n}=30$.

Methods Each infant received the GHT and Yakson interventions twice a day for 5 days. Each session lasted 15 minutes. The control group received routine nursing care.

Results In interventional group, an increase was found in sleep state score after the Yakson and GHT intervention. Their awake and fussy states' scores decreased after both interventions. No significant difference was found between Yakson and GHT group in their behavioral state scores.

Conclusions The findings suggest that Yakson and GHT had soothing and calming effect on preterm infants and could be beneficial in nursing interventions. 